\title{
Oral flora of stray dogs and cats in Algeria: Pasteurella and other zoonotic bacteria
}

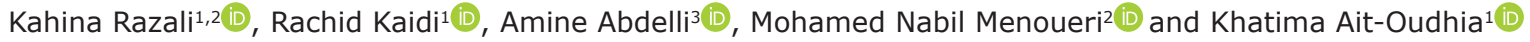 \\ 1. Laboratory of Animal Reproduction Biotechnologies, Blida, Algeria; 2. Department of Veterinary Sciences, Institute of \\ Veterinary Sciences, Université Saad Dahlab de Blida 1, Blida, Algeria; 3. Department of Agriculture Science, \\ Bouira University, Bouira, Algeria. \\ Corresponding author: Kahina Razali, e-mail: kahimane987@yahoo.com \\ Co-authors: RK: kaidirachid@yahoo.fr, AA: abdelliamine@hotmail.fr, MNM: nabil_menoueri@yahoo.fr, \\ KA: khatima.aitoudhia@gmail.com \\ Received: 05-09-2020, Accepted: 23-11-2020, Published online: 30-12-2020
}

doi: www.doi.org/10.14202/vetworld.2020.2806-2814 How to cite this article: Razali K, Kaidi R, Abdelli A, Menoueri MN, Ait-Oudhia K (2020) Oral flora of stray dogs and cats in Algeria: Pasteurella and other zoonotic bacteria, Veterinary World, 13(12): 2806-2814.

\begin{abstract}
Background and Aim: Knowledge of potentially pathogenic bacteria presents in the oral cavity of dogs and cats may be helpful in determining appropriate treatment for infected bite wounds. About 120,000 people are exposed to dog and cat bites every year in Algeria, but little is known about the dog and cat oral flora causing bite wound complications. The purpose of this study was to identify potential zoonotic bacteria from oral cavity of dogs and cats and to determine their susceptibility to antibiotics to contribute to the treatment of bite wound infection.
\end{abstract}

Materials and Methods: Oral swabs from 100 stray dogs and 100 stray cats were collected and cultured in several media: Chocolate agar, MacConkey agar, and Mannitol Salt Agar. Bacterial isolates were identified using several commercial kits of the analytical profile index and tested for antibiotic susceptibility by disk diffusion method.

Results: Overall, 185/200 (92.5\%) dogs and cats carried zoonotic bacteria in their mouths, of which 55.13\% (102/185) had at least two bacterial pathogens. 374 pathogenic strains belonging to 15 genera were isolated: Eleven were Gram-negative (Proteus, Pasteurella, Escherichia, Moraxella, Klebsiella, Acinetobacter, Enterobacter, Pseudomonas, Aeromonas, and Neisseria Haemophilus) and four were Gram-positive (Staphylococcus, Streptococcus, and Corynebacterium, Bacillus). Fifty-one strains of Pasteurella were isolated from 44 carriers of Pasteurella (21 Pasteurella multocida, 21 Pasteurella pneumotropica, and 9 Pasteurella spp.). Pasteurella strains were tested for antibiotic resistance. Resistance to at least one drug was observed in $8(15.68 \%)$ of Pasteurella isolates and two strains $(3.92 \%)$ were found to be multidrug-resistant (to two or more drugs). Erythromycin, penicillin, and ampicillin were the antimicrobials to which the isolates showed greater resistance $(7.84 \%, 5.88 \%$, and $3.92 \%$, respectively).

Conclusion: To the best of our knowledge, this study is the first in Algeria to detect potential human pathogenic bacteria in the oral cavity of dogs and cats. It reveals that these animals have multiple zoonotic bacteria in their mouths including Pasteurella species, which may be multidrug-resistant.

Keywords: Algeria, bite, dogs and cats, oral flora, Pasteurella.

\section{Introduction}

Animal bites are a major health problem worldwide $[1,2]$, due to the high number of people seeking health services for animal-related injuries [2,3]. Dogs and cats are implicated in $90 \%$ of this and account for approximately $1 \%$ of the annual emergency department visits [3-7]. The most common bite-related complication is wound infection $[6,7]$, resulting in local and systemic infections requiring specific antimicrobial therapy [7-9]. It is estimated that approximately $3-18 \%$ of dog bites and $20-80 \%$ of cat bites become infected [5-7] by the oral flora of the biting animal [10,11]; wounds are usually

Copyright: Razali, et al. Open Access. This article is distributed under the terms of the Creative Commons Attribution 4.0 International License (http://creativecommons.org/licenses/by/4.0/), which permits unrestricted use, distribution, and reproduction in any medium, provided you give appropriate credit to the original author(s) and the source, provide a link to the Creative Commons license, and indicate if changes were made. The Creative Commons Public Domain Dedication waiver (http://creativecommons.org/ publicdomain/zero/1.0/) applies to the data made available in this article, unless otherwise stated. polymicrobial $[4-10,11]$ and contain a mixture of aerobic and anaerobic bacteria $[2,3]$.

Although oral flora of dogs and cats may contain several zoonotic pathogens [2-12], Pasteurella species, in particular Pasteurella multocida, has been reported as one of the major bacteria leading to human infection following animal bites [5]. Thus, with up to $66 \%$ of dogs and $90 \%$ of cats harboring Pasteurella species in their mouths [13], the number of bites inoculate this microorganism is significant. In humans, $P$. multocida is isolated from $50 \%$ of dog bite wounds, $75 \%$ of cat bite wounds or scratches, and less frequently from licks $[13,14]$.

Typical clinical manifestations are cellulitis, soft-tissue abscesses, and purulent wounds at the site of injury; the infection is serious and can be complicated in tenosynovitis, osteomyelitis, and septic arthritis [9-14]. In addition to local wound infection, P. multocida can cause systemic infections, including septicemia, meningitis, brain abscess, pneumonia, endocarditis, and other severe sequelae especially in immunocompromised patients [9-13]. 
In Algeria, the number of stray dogs and cats wandering freely through the streets and urban areas is constantly increasing over the last few years, placing people at risk of bites $[15,16]$.

Furthermore, around 120.000 people are exposed to animal bites each year, $80 \%$ of whom are bitten by stray dogs $[15,16]$.

Knowledge of zoonotic bacteria present in the oral cavity of dogs and cats is very important for determining the danger of bite complications in humans [4-11], and the determination of their antibiotic susceptibility helps doctors to select the appropriate treatment for infected bite wounds [2-14].

Despite the high frequency of annual visits to the emergency departments, in our country, due to animal bites $[15,16]$, the oral flora of dogs and cats causing bite wound complications is still relatively unstudied.

The purpose of this study was to identify potential zoonotic bacteria from oral cavity of dogs and cats and to determine their susceptibility to antibiotics to contribute to the treatment of bite wound infection.

\section{Materials and Methods \\ Ethical approval}

The study protocol was approved by the ethics committee and decision board (number 01/2018) of P.I.C.C-U.H.E.P. of Algiers.

\section{Study area}

The study was conducted in the Department of Algies which is situated on the central coast of Algeria between $3^{\circ} 2{ }^{\prime} 31.09^{\prime \prime}$ east longitude and $36^{\circ} 45^{\prime} 9^{\prime \prime}$ north latitude. It covers an area of $1190 \mathrm{~km}^{2}$ and comprises 57 districts with a population of over 2.9 million inhabitants. Algiers is bounded from the north by the Mediterranean Sea, from the south by the Blida department, from the east by the Boumerdes department, and from the west by the Tipaza department. Public Industrial and Commercial Company-Urban Hygiene and Environmental Protection (P.I.C.CU.H.E.P) is affiliated with the Algerian Ministry of Water Resources and Environment that controls zoonosis and vector-borne diseases such as rabies and leishmaniosis.

In the context of the National Rabies Prevention Program, P.I.C.C-U.H.E.P. Catches stray dogs and cats in the 57 districts of the Algiers department. The captured animals are subsequently sheltered in the dog-pound of El-Harrach during the legal period (7 days) before euthanasia to allow for owners to claim their pets in compliance with the Algerian legislation on the protection of animals. The geographical position of the dog-pound and the animal catching radius in Algiers is represented in Figure-1.

\section{Sampling}

From January 2018 to July 2019, 200 buccal swabs (tongue, gum, palate, cheeks, and teeth) were collected at irregular intervals from 100 stray dogs and 100 stray cats which were randomly selected without distinction of age, sex, or breed. All the sampled animals were caught by the P.I.C.C-U.H.E.P. from the 57 municipalities of Algiers during the study period that was apparently healthy and did not receive any previous treatment.

\section{Bacterial analysis of samples}

The specimens were transported in an icebox $\left(+4^{\circ} \mathrm{C}\right)$ within $60 \mathrm{~min}$ after collection to the microbiology laboratory for further analysis. Following a control quality step, Escherichia coli American Type Culture Collection (ATCC) 25922, Staphylococcus aureus resistant Type Culture Collection (ATCC) 43300, S. aureus sensitive Type Culture Collection (ATCC) 25923, and Pseudomonas aeruginosa Type Culture Collection (ATCC) 27853 were used.

Each swab was directly plated on chocolate agar (Columbia agar medium supplemented with 5\% of blood sheep and slowly heating to $80^{\circ} \mathrm{C}$ ) (Pasteur Institute, Algeria), MacConkey agar (Pasteur institute, Algeria), and Mannitol salt agar "Chapman Medium" (Pasteur institute, Algeria). Chocolate agar plates were incubated for $48-72 \mathrm{~h}$ at $37^{\circ} \mathrm{C}$ in a $5 \% \mathrm{CO}_{2}$ atmospheric chamber, and both MacConkey and Mannitol salt agar plates were incubated aerobically at $37^{\circ} \mathrm{C}$ for $24 \mathrm{~h}$.

After 24, 48, and $72 \mathrm{~h}$ of incubation, the plates were examined and different types of colonies were then subcultured separately to the appropriate media for the processing of pure cultures. When pure cultures were obtained, each isolate was identified according to the morphology of the colonies, the type of hemolysis, the Gram staining microscopy, and several biochemical tests for characterizing isolates.

Biochemical tests included: Catalase and oxidase activities, substrate utilization as determined by commercial biochemical test kits, and coagulase testing using rabbit plasma for Staphylococci identification. Pasteurella spp. were identified on the basis of Gram staining (Gram-negative coccobacilli), absence of hemolysis, absence of growth on MacConkey, and positive biochemical reactions: Catalase and oxidase activities, and indole test. Final identification of strains was done using API20NE commercial kit (Biomérieux, Marcy l'Etoile, France).

Several commercial analytical profile index (API) kits (API20NE, API20E, APINH, API Staph, API Strept) (Biomérieux, Marcy l'Etoile, France) were used to identify strains other than Pasteurella.

\section{Antimicrobial susceptibility testing of Pasteurella}

A subset of Pasteurella strains were tested for susceptibility to four antibiotics which are commonly prescribed for the treatment of animal bites. Resistance to amoxicillin/clavulanic acid $30 \mu \mathrm{g}$; penicillin $10 \mathrm{IU}$; ampicillin $10 \mu \mathrm{g}$; tetracycline $30 \mu \mathrm{g}$; and erythromycin $5 \mu \mathrm{g}$ was determined on Muller-Hinton agar supplemented with 5\% sheep blood (Pasteur Institute, Algeria) using the standard Kirby-Bauer disk diffusion method. 


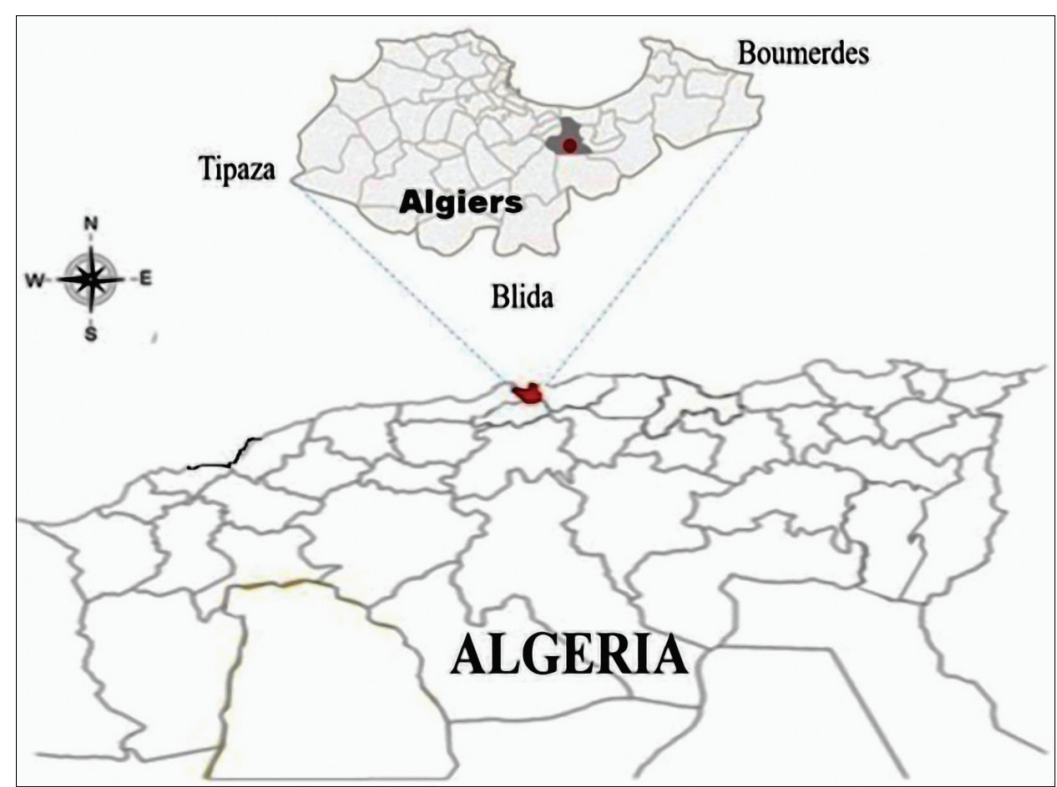

Figure-1: Map of Northern Algeria showing the location of the study area in Algiers [Source: Map prepared by the corresponding author].

\section{Statistical analysis and map conception}

Pearson's Chi-square test $(\alpha=5 \%)$ was applied to compare Pasteurella prevalence, using Microsoft Excel world 2007. Differences were statistically significant when $\mathrm{p}<0.05$.

The map showing the geographic location of the dog-pound and the animal catching area was conceived using Microsoft PowerPoint 2007, as available in Microsoft Office software (Microsoft, USA), while the quality of the artwork was enhanced by Adob Photoshop software.7.0.1 (Adobe, USA).

\section{Results}

\section{Prevalence and bacterial isolation}

During the study period, a total of 100 stray dogs and 100 stray cats were swabbed. Bacteriological culture showed that $92.5 \%(185 / 200)$ of the swabbed animals had at least one zoonotic bacterium in their mouths. The carrier rates for zoonotic bacteria were similar in dogs $(92 \%, 92 / 100)$ and cats $(93 \%, 93 / 100)$. From 185 carriers of zoonotic bacteria, 374 pathogenic strains were isolated (174 and 200 in dogs and cats, respectively) (Table-1).

Potential zoonotic bacterial isolates accounted for $62.83 \%$ (63.22\% in dogs and $62.5 \%$ in cats) Gramnegative and $37.17 \%(36.78 \%$ in dogs and $37.5 \%$ in cats) Gram-positive which were mainly represented by cocci $(25.67 \%)$, including $16.58 \%$ of coagulase-positive Staphylococci and rods (11.5\%) representing Corynebacterium spp. and Bacillus spp.

From the Gram-negative standpoint, $43.05 \%$ of the bacteria were rods; $18.98 \%$ were coccobacilli, and $0.8 \%$ were cocci.

The most common Gram-negative bacteria isolates were enterobacteria $(25.13 \%, 94 / 374)$, non-fermenting Gram-negative bacilli $(15.77 \%, 59 / 374)$, and Pasteurella (13.63\%, 51/374). Proteus mirabilis was the most frequently encountered $(14.97 \%, 56 / 374)$ of enterobacteria isolates, followed by E. coli $(7.22 \%$, 27/374).

Isolation rates of pathogenic Gram-negative bacteria were similar for dogs $(63.22 \%, 110 / 174)$ and cats $(62.50 \%, 125 / 200)$, in this study, isolation rates of pathogenic Gram-positive bacteria as well $(36.78 \%, 64 / 174$ dogs and 37.5\%, 75/200 cats). Among Gram-negative bacteria, Klebsiella oxytoca was isolated only from the oral cavity of the cat $(1.87 \%, 7 / 200)$, while Aeromonas hydrophila was detected only in the oral cavity of the $\operatorname{dog}(2.3 \%, 4 / 174)$. Detection rates of Moraxella and Acinetobacter were lower for dogs $(1.72 \%, 3 / 174$ and $0.57 \%, 1 / 174$, respectively) compared to cats $(4.5 \%$, 9/200; and $0.57 \%, 1 / 174$, respectively) (Table-2).

Out of the 200 bacteriologically cultured swabs, 185 showed at least one type of colony in which 374 zoonotic bacterial species were isolated after identification. Eighty-three $(44.86 \%)$ animals, including 44 dogs and 39 cats carried only one bacterial species, while the remaining 102 animals (48 dogs and 54 cats) carried at least two different bacterial species within a maximum of eight bacterial species for dogs and six bacterial species for cats (Table-3).

\section{Pasteurella spp. carriage descriptive data}

Of the 200 dogs and cats examined during the study period, 44 (22\%) carried Pasteurella spp. in their oral cavities; the carrying rates for dogs and cats were $27 \%(27 / 100)$ and $17 \%(17 / 100)$, respectively. Fiftyone Pasteurella strains were isolated and distributed as follows: 38 animals carried one Pasteurella strain; five animals carried two Pasteurella strains and one cat carried three Pasteurella strains. Identification of the isolates revealed that 21 of the strains were P. multocida, 21 strains Pasteurella pneumotropica, and nine strains (Pasteurella spp.) remained unclassified (Tables-4 and 5). 
Table-1: Prevalence of oral zoonotic bacteria in stray dogs and cats in Algeria.

\begin{tabular}{|c|c|c|c|c|c|c|}
\hline \multirow[t]{2}{*}{ Characteristics } & \multicolumn{2}{|c|}{ Total } & \multicolumn{2}{|c|}{ Dog } & \multicolumn{2}{|c|}{ Cat } \\
\hline & No. & $\%$ & No. & $\%$ & No. & $\%$ \\
\hline Sampled animals' & 200 & - & 100 & - & 100 & - \\
\hline Carriers of zoonotic bacteria & 185 & 92.5 & 92 & 92 & 93 & 93 \\
\hline Zoonotic bacterial isolates & 374 & - & 174 & - & 200 & - \\
\hline
\end{tabular}

Table-2: Zoonotic bacteria isolated from oral cavities of stray dogs and cats in Algeria and their frequency.

\begin{tabular}{|c|c|c|c|c|c|c|}
\hline \multirow{2}{*}{$\begin{array}{l}\text { Zoonotic bacterial isolates } \\
\text { Microscopic shape/species }\end{array}$} & \multicolumn{2}{|c|}{ Total } & \multicolumn{2}{|c|}{ Dog } & \multicolumn{2}{|c|}{ Cat } \\
\hline & No. & $\%$ & No. & $\%$ & No. & $\%$ \\
\hline Total isolates & 374 & - & 174 & - & 200 & - \\
\hline Gram-positive bacteria & 139 & 37.17 & 64 & 36.78 & 75 & 37.5 \\
\hline Cocci & 96 & 25.67 & 45 & 25.86 & 51 & 25.5 \\
\hline CoPS & 62 & 16.58 & 34 & 19.54 & 28 & 14 \\
\hline Streptococcus spp. & 34 & 9.09 & 11 & 6.32 & 23 & 11.5 \\
\hline Rods & 43 & 11.5 & 19 & 10.92 & 24 & 12 \\
\hline Corynebacterium spp. & 31 & 8.29 & 12 & 6.9 & 19 & 9.5 \\
\hline Bacillus spp. & 12 & 3.21 & 7 & 4.02 & 5 & 2.5 \\
\hline Gram negative bacteria & 235 & 62.83 & 110 & 63.22 & 125 & 62.5 \\
\hline Cocci & 3 & 0.8 & 1 & 0.57 & 2 & 1 \\
\hline Neisseria spp. & 3 & 0.8 & 1 & 0.57 & 2 & 1 \\
\hline Coccobacilli & 71 & 18.98 & 36 & 20.69 & 35 & 17.5 \\
\hline Acinetobacter baumannii & 6 & 1.6 & 1 & 0.57 & 5 & 2.5 \\
\hline Pasteurella multocida & 21 & 5.61 & 10 & 5.75 & 11 & 5.5 \\
\hline Pasteurella pneumotropica & 21 & 5.61 & 17 & 9.77 & 4 & 2 \\
\hline Pasteurella spp. & 9 & 2.41 & 4 & 2.3 & 5 & 2.5 \\
\hline Haemophilus influenza & 2 & 0.53 & 1 & 0.57 & 1 & 0.5 \\
\hline Moraxella spp. & 12 & 3.21 & 3 & 1.72 & 9 & 4.5 \\
\hline Rods & 161 & 43.05 & 73 & 41.95 & 88 & 44 \\
\hline Escherichia coli & 27 & 7.22 & 11 & 6.32 & 16 & 8 \\
\hline Klebsiella oxytoca & 7 & 1.87 & - & - & 7 & 3.5 \\
\hline Proteus mirabilis & 56 & 14.97 & 29 & 16.67 & 27 & 13.5 \\
\hline Enterobacter cloacae & 4 & 1.07 & 1 & 0.57 & 3 & 1.5 \\
\hline Pseudomonas aeruginosa & 4 & 1,07 & 2 & 1.15 & 2 & 1 \\
\hline Aeromonas hydrophila & 4 & 1.07 & 4 & 2.30 & - & - \\
\hline Other NFGNB & 59 & 15.78 & 26 & 14.94 & 33 & 16.5 \\
\hline
\end{tabular}

CoPS=Coagulase positive Staphylococcus, NFGNB=Non-fermenting Gram-negative bacilli

Table-3: Number of zoonotic bacteria isolated per animal.

\begin{tabular}{|c|c|c|c|c|c|c|}
\hline \multirow[t]{2}{*}{ No of carried zoonotic bacteria } & \multicolumn{2}{|c|}{ Total population } & \multicolumn{2}{|c|}{ Dog } & \multicolumn{2}{|c|}{ Cat } \\
\hline & No & $\%$ & No & $\%$ & No & $\%$ \\
\hline Total animals & 185 & - & 92 & - & 93 & - \\
\hline 1 bacteria & 83 & 44.86 & 44 & 47.82 & 39 & 41.93 \\
\hline 2 bacteria & 51 & 27.56 & 29 & 31.52 & 22 & 23.65 \\
\hline 3 bacteria & 30 & 16.21 & 11 & 11.95 & 19 & 20.43 \\
\hline 4 bacteria & 13 & 7.027 & 5 & 5.43 & 8 & 8.6 \\
\hline 5 bacteria & 3 & 1.62 & 1 & 1.08 & 2 & 2.15 \\
\hline 6 bacteria & 4 & 2.16 & 1 & 1.08 & 3 & 3.22 \\
\hline 8 bacteria & 1 & 0.54 & 1 & 1.08 & - & - \\
\hline
\end{tabular}

Table-4: Isolation rates of Pasteurella spp. from oral cavities of stray dogs and cats in Algeria.

\begin{tabular}{|c|c|c|c|c|c|c|}
\hline \multirow[t]{2}{*}{ Characteristics } & \multicolumn{2}{|c|}{ Total } & \multicolumn{2}{|c|}{ Dog } & \multicolumn{2}{|c|}{ Cat } \\
\hline & No. & $\%$ & No. & $\%$ & No. & $\%$ \\
\hline Samled animals' & 200 & 100 & 100 & 100 & 100 & 100 \\
\hline No. of subjects & 44 & 22 & 27 & 27 & 17 & 17 \\
\hline No. of isolates & 51 & 100 & 31 & 100 & 20 & 100 \\
\hline Pasteurella multocida & 21 & 41.17 & 10 & 32.25 & 11 & 55 \\
\hline Pasteurella pneumotropica & 21 & 21.56 & 17 & 54.83 & 4 & 20 \\
\hline Pasteurella spp. & 9 & 9.8 & 4 & 12.9 & 5 & 25 \\
\hline
\end{tabular}


There were some differences in the distribution of Pasteurella species between dogs and cats: P. multocida was the predominant species in cats $(55 \%$ of feline isolates), while P. pneumotropica was the predominant species in dogs (55\% of canine isolates).

In fact, there was no difference between dogs $(10 \%)$ and cats $(11 \%)$ in carrying $P$. multocida, but there was a difference in carrying $P$. pneumotropica: Of the 100 dogs sampled, 17 (17\%) carried P. pneumotropica, although it was only found in four cats (4\%) (Table-4).

\section{Susceptibility to antibiotics}

Antibiotic susceptibility results showed that 18 $(69.23 \%)$ isolates were susceptible to all antimicrobial drugs tested, while $30.67 \%$ of the strains were resistant to one or two antibiotics. Of the eight antibiotic-resistant isolates, five distinct antibiotic-resistant patterns were observed: Bi-drug-resistance was observed in $P$. pneumotropica carried by a dog, while tri-drug resistance was observed in P. multocida isolated from a cat (Tables-6 and 7).
From the effectiveness therapy point of view, erythromycin, penicillin, and ampicillin were antimicrobials for which isolates showed higher resistance rates with $7.84 \%, 5.88 \%$, and $3.92 \%$ of isolates, respectively (Table-6).

\section{Discussion}

Human infected-wounds caused by dog and cat bites are usually polymicrobial, containing a mixture of aerobic and anaerobic bacteria [2,3], mainly through the oral flora of biting animals [5,10,11].

In this study, most of the dogs and cats sampled (92.5\% and 185/200) were carriers of zoonotic bacteria in their oral cavities: In 83 animals, a single species was found, $50 \%$ of the animals sampled carried two species, and the rest had three or more species. These findings are in accordance with earlier studies $[4,11,12,17,18]$ that reported various opportunistic and potentially pathogenic human bacteria are found in the oral cavity of dog and cat.

Bacteria which are not pathogenic to humans were not included in this work, as well as anaerobic

Table-5: Pasteurella species isolated from oral cavities of stray dogs and cats in Algeria and their frequency.

\begin{tabular}{|c|c|c|c|c|c|c|}
\hline \multirow[t]{2}{*}{ Characteristics } & \multicolumn{2}{|c|}{ Total population } & \multicolumn{2}{|c|}{ Dog } & \multicolumn{2}{|c|}{ Cat } \\
\hline & No & $\%$ & No & $\%$ & No & $\%$ \\
\hline Carriers of Pasteurella & 44 & - & 27 & - & 17 & - \\
\hline 1 species & 38 & 86.36 & 23 & 85.18 & 15 & 88.23 \\
\hline P. pneumotropica & 16 & 36.36 & 13 & 48,15 & 3 & 17,65 \\
\hline P. multocida & 16 & 36.36 & 7 & 25,93 & 9 & 52,94 \\
\hline Pasteurella spp. & 6 & 13.64 & 3 & 11,11 & 3 & 17,65 \\
\hline 2 species & 5 & 11.36 & 4 & 14.81 & 1 & 5.88 \\
\hline P. multocida+ Pasteurella spp. & 1 & - & - & - & 1 & 5.88 \\
\hline P. multocida $+P$. pneumotropica & 3 & 6.82 & 3 & 11.11 & - & - \\
\hline Pasteurella spp. $+P$. pneumotropica & 1 & 2.27 & 1 & 3.70 & - & - \\
\hline 3 species & 1 & 2.27 & - & - & 1 & 5.88 \\
\hline P. multocida+Pasteurella spp. $+P$. pneumotropica & 1 & 2.27 & - & - & 1 & 5.88 \\
\hline
\end{tabular}

P. multocida=Pasteurella multocida, $P$. pneumotropica=Pasteurella pneumotropica

Table-6: Antibiotic susceptibility of Pasteurella spp. isolated from oral cavities of stray dogs and cats in Algeria.

\begin{tabular}{|c|c|c|c|c|c|c|}
\hline \multirow{2}{*}{$\begin{array}{l}\text { Pasteurella isolates } \\
\text { Antimicrobial agents }\end{array}$} & \multicolumn{2}{|c|}{ Total $(n=26)$} & \multicolumn{2}{|c|}{ Isolates from dog $(n=17)$} & \multicolumn{2}{|c|}{ Isolates from cat $(n=9)$} \\
\hline & R (\%) & S (\%) & R (\%) & S (\%) & R (\%) & S (\%) \\
\hline Penicillin & $3(11.53)$ & $23(88.47)$ & $2(11.76)$ & $15(88.24)$ & $1(11.11)$ & $8(88.89)$ \\
\hline Ampicillin & $2(7.69)$ & $24(92.31)$ & $1(5.88)$ & $16(94.12)$ & $1(11.11)$ & $8(95.0)$ \\
\hline Erythromycin & $4(15.38)$ & $22(84.62)$ & $2(11.76)$ & $15(88.24)$ & $2(22.22)$ & $7(77.78)$ \\
\hline Tetracycline & $1(3.84)$ & $25(96.16)$ & $1(5.88)$ & $16(94.12)$ & $0(0.0)$ & $9(100)$ \\
\hline Amoxicillin-Clavulanate & $1(3.84)$ & $25(96.16)$ & $1(5.88)$ & $16(94.12)$ & $0(0.0)$ & $9(100)$ \\
\hline
\end{tabular}

$\mathrm{R}=$ Resistant, $\mathrm{S}=$ Susceptible

Table-7: Antibiotic resistance patterns in Pasteurella spp. isolated from oral cavities of stray dogs and cats in Algeria.

\begin{tabular}{|c|c|c|c|c|c|c|c|}
\hline \multirow[t]{2}{*}{ Patterns/isolates } & \multirow[t]{2}{*}{ Total } & \multicolumn{2}{|c|}{ Pasteurella multocida } & \multicolumn{2}{|c|}{ Pasteurella pneumotropica } & \multicolumn{2}{|c|}{ Pasteurella spp. } \\
\hline & & Dog & Cat & Dog & Cat & Dog & Cat \\
\hline No. Isolates & 26 & 5 & 6 & 11 & 1 & 1 & 2 \\
\hline S ble $^{\text {b } \%)}$ & $18(69.23)$ & $3(60)$ & $4(66.66)$ & $7(63.63)$ & $1(100)$ & $1(100)$ & $2(100)$ \\
\hline Tetracycline & $1(3.84)$ & $1(20)$ & - & - & - & - & - \\
\hline Amox-clav & $1(3.84)$ & - & - & $1(9.09)$ & - & - & - \\
\hline Ery & $3(11.53)$ & $1(20)$ & $1(16.66)$ & $1(9.09)$ & - & - & - \\
\hline Penicillin & $1(3.84)$ & - & - & $1(9.09)$ & - & - & - \\
\hline Pen-Amp & $1(3.84)$ & - & - & $1(9.09)$ & - & - & - \\
\hline Pen-Amp-Ery & $1(3.84)$ & - & $1(16.66)$ & - & - & - & - \\
\hline
\end{tabular}

Veterinary World, EISSN: 2231-0916 
bacteria; 374 bacterial strains were isolated (174 in dogs and 200 in cats), belonging to ten several families: Staphylococcaceae, Streptococcaceae, Corynebacteriaceae, Bacillaceae, Neisseriaceae, Pasteurellaceae, Moraxellaceae, Enterobacteriaceae, Pseudomonadaceae, and Aeromonadaceae.

Gram-negative bacteria were the most frequently isolated pathogen, with $62.80 \%$ of all isolates, while, Gram-positive bacteria represent only $37.20 \%$ of the pathogenic bacteria accrued in oral cavities of dogs and cats.

Several studies [19-23] described Gramnegative bacteria as the most common bacteria involved in animal bite complications, such as Pasteurella spp., Neisseria spp., Moraxella spp., and Enterobacteriaceae.

It is common knowledge that Gram-negative bacteria are often pathogenic; in addition to, septicemia and bacteremia that contain endotoxins whose release into soft-tissue and blood resulting in acute shock and death [24].

The high proportion of Gram-negative bacteria in dogs' and cats' mouths highlights the potential risk of complicating bite wounds infected with these microorganisms. Among Gram-negative bacteria, the predominant family was Enterobacteriaceae, followed by Pasteurellaceae, while Moraxellaceae, Pseudomonadaceae, Aeromonadaceae, and Neisseriaceae were the less abundant families.

Members of the Enterobacteriaceae family, which includes E. coli and P. mirabilis, are known to be natural inhabitants of the gastrointestinal tract of humans and animals [20-25]. These bacteria are also found in the esophagus and/or the mouth of dogs and cats $[23,25,26]$.

In this report, the prevalence of E. coli in dogs and cats was relatively high $(6.32 \%$ and $8 \%$ oral carriers, respectively) and similar to the $6.12 \%$ (dog) and $6.52 \%$ (cat) rates reported in South Africa and India, respectively $[27,28]$. However, $P$. mirabilis isolation rates in our study $(16.67 \%$ in dogs and $13.5 \%$ in cats) appeared to be higher than those reported in South Africa $(2.04 \%$ in dogs) and India $(4.34 \%$ in cats) $[27,28]$. Our abundance of $P$. mirabilis isolation may be attributed to the contamination of food, water, soil, and the environment by fecal flora and licking between animals [25].

Both E. coli and P. mirabilis are very important human pathogens that lead to numerous health manifestations, such as wound infections and abscesses, urinary tract infection, septicemia, meningitis, and fatal endotoxemia [20-25]. It is also established that these bacteria are multidrug-resistant enterobacteria that generate nosocomial infections [26].

In the current study, Pasteurella was the most popular genus ( $17.81 \%$ of all isolates) in dogs, while in cats; it was the second most prevalent genus (10\% of all isolates). Several previous studies have described Pasteurellaceae (mainly Pasteurella) as the most predominant genus in the oral cavities of healthy dogs and cats [4-11-27].

The isolation rate of Pasteurella in dogs (17.81\%) appeared to be close to the $18.36 \%$ reported by Almansa Ruiz et al. [28] in South Africa. Whyte et al. [12] revealed a lower prevalence of Pasteurella $(7.52 \%)$ in cats. Interestingly, the prevalence of Pasteurella in dogs $(27 \%)$ was higher than that of cats $(17 \%)$, which conflicts with other reports stating that the main carriers of Pasteurella are cats (up to $90 \%)[4,12,13,17]$.

This can be due to many factors, such as age, sex, breed, diet, and living conditions [12-29]. In addition, many studies show that the normal oral flora varies depending on the sampling season, sampling mouth area, periodontal health [12-30], and geographical location [29].

Pasteurella organisms grow in culture on a variety of commercial media, including sheep blood and chocolate agar [14], but, they are fastidious and can be difficult to isolate and identify from oral flora containing many and various bacteria [29].

In this research, 51 strains of Pasteurella were isolated from 44 carriers of Pasteurella, including P. multocida (21/374, 5.61\%), P. pneumotropica (21/374, 5.61\%), and Pasteurella spp. (9/374, 2.41\%). Some differences in the distribution of Pasteurella species among dogs and cats were observed; P. multocida was the most dominant cat species $(11 / 20$, and $55 \%$ of Pasteurella isolates), while P. pneumotropica was found to be more abundant in dogs' mouths (17/31, and $55 \%$ of Pasteurella isolates). Statistical analysis did not show any significant difference in P. multocida prevalence between dogs and cats $(\mathrm{p}=0.817)$; however, a significant difference was observed in the prevalence of $P$. pneumotropica $(\mathrm{p}=0.002)$.

Pasteurella species are small, non-motile, facultative anaerobic, Gram-negative coccobacilli, found in the upper respiratory tracts of many domestic and wild animals, including dogs and cats, which have particularly high colonization rates [13-31].

In humans, $P$. multocida is the most common pathogens isolated from soft-tissue infections resulting from $50 \%$ of dog bites, $75 \%$ of cat bites or scratches, and less frequently from licks on skin abrasions by pets $[9,13,14,31]$.

P. multocida can lead to local wound infection (subcutaneous abscesses, and lymphangitis) may be complicated into cellulitis, arthritis, tenosynovitis, and osteomyelitis [9-4]. In immunocompromised patients, many cases of systemic infections were reported, including septicemia, meningitis, brain abscess, pneumonia, and endocarditis [9-13].

P. multocida is most commonly associated with bite infections among members of the Pasteurella genus; however, other Pasteurella species such as Pasteurella dagmatis, Pasteurella canis, and Pasteurella stomatis found in dogs and cats' mouths, have also been increasingly cultivated from bite wounds [14-31]. 
In this study, the isolation rate of $P$. pneumotropica was $17 \%$ in dogs and $4 \%$ in cats, but $P$. dagmatis, $P$. stomatis, and $P$. canis were not isolated $P$. pneumotropica is known to be more common in laboratory mouse and rodent [32], although, some studies have reported isolation of $P$. pneumotropica from other species, like dogs [33].

Based on the biochemical characteristics, the strains initially identified as $P$. pneumotropica were divided into three biotypes named Jawetz, Heyl, and Henriksen. Both the biotypes Jawetz and Heyl are associated with rodents, while, the biotype Henriksen which was reclassified as $P$. dagmatis was primarily associated with cats and dogs [33].

One of the limitations of this study is that the API20NE commercial kits used to identify Pasteurella strains did not include many species of Pasteurella other than P. multocida and P. pneumotropica in their database. Thus, often, $P$. dagmatis, $P$. stomatis, and $P$. canis may often be misidentified as $P$. multocida or P. pneumotropica [33].

In addition, Benga et al. [33] reported that $P$. dagmatis was formerly designed as $P$. pneumotropica bioptype Henriksen, thus explaining the numerous early reports of clinical diseases caused by P. pneumotropica resulting from bites by dogs or cats.

$P$. pneumotropica may occasionally cause disease in both immunodeficient and immunocompetent individuals [32]. Other common Gram-negative bacteria implicated in bite complications were isolated at low frequency, including, Moraxella (3.21\%), Acinetobacter (1.6\%), K. oxytoca $(1.87 \%)$, A. hydrophila (1.07\%), Enterobacteriaceae (1.07\%), P. aeruginosa $(1.07 \%)$, and Neisseria $(0.8 \%)$.

Moraxella and Neisseria were reported as part of the normal oral flora of dogs and cats and as an important pathogens in human wounds secondary to animal bites [4], causing severe disease in people including skin and tendon infections, as well as septicemia [9-34].

A. hydrophila has been shown to cause serious fatal infections in humans following bite wound infections [20].

In agreement with other investigations, culture-based study of the oral flora of dogs and cats showed that Staphylococci and Streptococci were among the most prevalent bacteria in pets [35].

In this study, $31 \%$ and $17 \%$ of sampled animals were carriers of Staphylococcus spp. and Streptococcus spp. in their mouths, respectively. These bacteria were the second most common species isolated from dog and cat bite-wounds, respectively [36].

The prevalence of these two species was more common in non-purulent cellulitis/lymphangitis wounds than in abscesses or purulent wounds [36]. Staphylococci- and Streptococci-related cellulitis is more diffuse and typically less severe than that seen with P. multocida infections [21].

Although, Pasteurella species, in particular P. multocida, is one of the most common opportunistic pathogens found in the oral cavity of dogs and cats leading to human infection after bites or scratches [13], no data are available on the resistance patterns of Pasteurella originating from dogs and cats in Algeria.

The majority of the Pasteurella isolates in this analysis were susceptible to all drugs tested, with only eight $(15.68 \%)$ isolates demonstrating resistance to at least one antibiotic, of which six belonged to dogs.

These results are consistent with published studies reported high resistance of this bacterium to some antimicrobials $[37,38]$. From a therapeutic point of view, erythromycin, penicillin, and ampicillin were the less effective antimicrobials in the treatment of bite wounds, while multidrug resistance profiles were reported in two isolates.

Typically, Pasteurella species are susceptible to penicillin, ampicillin, and amoxicillin-clavulanate which are the standard therapy of human Pasteurellaassociated bite wound infection [14-39]. Tetracycline, in the case of penicillin allergy, is an effective alternative [14].

In a recent study, by Ujvári et al. [31], all Pasteurella strains isolated from cats and humans were susceptible to ampicillin and tetracycline.

It should also be noted that none of the $72 \mathrm{P}$. multocida isolated from infections of the respiratory tract in dogs and cats investigated in the BfT-Germ Vet program demonstrated resistance to any of the tested antimicrobials (penicillin, ampicillin, erythromycin, and tetracycline) [40].

A study conducted by Ferreira et al. [37] in Brazil investigated $P$. multocida isolates from cat gingiva and dog oropharynx for their antimicrobial susceptibility. This study showed low levels of resistance to penicillin (7.3\%); however, lower susceptibilities to erythromycin in isolates from both dogs and cats were observed $(21.27 \%)$. In same study, resistance to tetracycline was absent.

Although, resistance of Pasteurella to $\beta$-lactam antibiotics has been described, no resistance of P. multocida to tetracycline and doxycycline has been reported in humans or pet animals. Furthermore, resistance to tetracycline has been described in pig and ruminant strains [31]. Interestingly, we found a P. multocida strain resistant to tetracycline in dog.

At least nine tetracycline resistance genes (TET genes) have been detected in Pasteurella species [40]. Many of them are related to plasmids or transposons and can, therefore, be exchanged horizontally, not only within the Pasteurellaceae family, but also with other Gram-negative bacteria [40].

In addition, experiments on the molecular basis of antimicrobial resistance indicate that Pasteurella has obviously acquired a number of resistance genes from other Gram-negative or Gram-positive bacteria [40].

Erythromycin is a member of the antibiotic macrolide class; recently, macrolide resistance has emerged in P. multocida [31]. There are no descriptions 
of resistance to this antibiotic in companion animals [37], but lower susceptibility to erythromycin in Pasteurella isolates from both dogs and cats was common [38].

The exchange of resistance genes between different organisms in the oral cavity as well as between oral bacteria and bacteria from other environments has already been described [8].

\section{Conclusion}

To the best of our knowledge, this study is the first in our country to detect zoonotic bacteria found in dogs and cats' oral cavities. It demonstrates that stray dogs and cats in Algeria carry many opportunistic and/or potentially pathogenic bacteria in their mouths, including Pasteurella spp., leading to infection of bite wounds and scratches.

It was shown that dogs were more carriers of Pasteurella spp. than cats, some of them were multidrug-resistant, a risk to public health.

Amoxicillin-clavulanate and tetracycline were the most sensitive drugs against Pasteurella species. Thus, these antimicrobials may be sufficient in humans to treat infected bites caused by Pasteurella

\section{Authors' Contributions}

$\mathrm{KR}, \mathrm{MNM}$, and KAconceived the study designed. KR performed the experiment and analyzed the data. $\mathrm{KR}$ and RK drafted and revised the manuscript. AA conducted the statistical analysis. All authors read and approved the final manuscript.

\section{Acknowledgments}

The authors would like to thank Dr. Madjid Akkou and Dr. Paolo. Leotta for manuscript preparation. This study did not receive any external funding.

\section{Competing Interests} interests.

The authors declare that they have no competing

\section{Publisher's Note}

Veterinary World remains neutral with regard to jurisdictional claims in published map and institutional affiliation.

\section{References}

1. Owczarczak-Garstecka, S.C., Christley, R., Watkins, F., Yang, H., Bishop, B. and Westgarth, C. (2019) Dog bite safety at work: An injury prevention perspective on reported occupational dog bites in the UK. Saf. Sci., 118: 595-606.

2. Muniz, I.M., Penna, B. and Lilenbaum, W. (2013) Treating animal bites: Susceptibility of staphylococci from oral mucosa of cats. Zoon. Public Health, 60(7): 504-509.

3. Goldstein, E.J.C., Citron, D.M., Tyrrell, K.L., Leoncio, E. and Merriam, C.V. (2018) Comparative in vitro activity of omadacycline against dog and cat bite wound isolates. Antimicrob. Agents Chemother., 62(4): e2551-17.

4. Sturgeon, A., Pinder, S.L., Costa, M.C. and Weese, J.S. (2014) Characterization of the oral microbiota of healthy cats using next-generation sequencing. Vet. J., 201(2): 223-229.
5. Damborg, P., Broens, E.M., Chomel, B.B., Guenther, S., Pasmans, F., Wagenaar, J.A., Weese, J.S., Wieler, L.H., Windahl,U., Vanrompay, D. and Guardabassi, L. (2016) Bacterial zoonoses transmitted by household pets: Stateof-the-art and future perspectives for targeted research and policy actions. J. Comp. Pathol., 155(1): S27-S40.

6. Morzycki, A., Simpson, A. and Williams, J. (2019) Dog bites in the emergency department: A descriptive analysis. CJEM, 21(1): 63-70.

7. Tabaka, M.E., Quinn, J.V., Kohn, M.A. and Polevoi, S.K. (2015) Predictors of infection from dog bite wounds: Which patients may benefit from prophylactic antibiotics? Emerg. Med. J., 32(11): 860-863.

8. Rossi, C.C., da Silva Dias, I., Muniz, I.M., Lilenbaum, W. and Giambiagi-deMarval, M. (2017) The oral microbiota of domestic cats harbors a wide variety of Staphylococcus species with zoonotic potential. Vet. Microbiol., 201: 136-140.

9. Oh, C., Lee, K., Cheong, Y., Lee, S.W., Park, S.Y., Song, C.S., Choi, I.S. and Lee, J.B. (2015) Comparison of the oral microbiomes of canines and their owners using next-generation sequencing. PloS One, 10(7): e0131468.

10. Older, C.E., Diesel, A.B., Lawhon, S.D., Queiroz, C., Henker, L.C. and Rodrigues Hoffmann, A. (2019) The feline cutaneous and oral microbiota are influenced by breed and environment. PloS one, 14(7): e0220463.

11. Sturgeon, A., Stull, J.W., Costa, M.C. and Weese, J.S. (2013) Metagenomic analysis of the canine oral cavity as revealed by high-throughput pyrosequencing of the 16S rRNA gene. Vet. Microbiol., 162(2-4): 891-898.

12. Whyte, A., Gracia, A., Bonastre, C., Tejedor, M.T., Whyte, J., Monteagudo, L.V. and Simón, C. (2017) Oral disease and microbiota in free-roaming cats. Top. Companion. Anim. Med., 32(3): 91-95.

13. Maraki, S., Kastanis, G., Stafylaki, D., Masunt, S., Kapsetakis, P. and Scoulica, E. (2018) Pasteurella multocida wound infection transmitted by a pet dog. Germs, 8(4): 214-217.

14. Ramiro, G.V., Gregorio, A.A., Luis, G.V.G., Gerardo, D.G.L. and Gerardo, D.C.L. (2016) Pasteurella canis as a case of septic arthritis and soft tissue infection after sheep bite: A case report. Global J. Med. Clin. Case Rep., 3(1): 012-014.

15. Kardjadj, M. and Ben-Mahdi, M.H. (2019) Epidemiology of dog-mediated zoonotic diseases in Algeria: Aone health control approach. New Microb. New Infect., 28: 17-20.

16. Yahiaoui, F., Kardjadj, M., Laidoudi, Y., Medkour, H. and Ben-Mahdi, M.H. (2018) The epidemiology of dog rabies in Algeria: Retrospective national study of dog rabies cases, determination of vaccination coverage and immune response evaluation of three commercial used vaccines. Prev. Vet. Med., 158: 65-70.

17. Hariharan, H. and Hariharan, S.H. (2017) Zoonotic Bacteria associated with cats. Vet. Med. Open J., 2(3): 68-75.

18. Flancman, R., Singh, A. and Weese, J.S. (2018) Evaluation of the impact of dental prophylaxis on the oral microbiota of dogs. PloS One, 13(6): e0199676.

19. Lau, J., Korman, T.M., Yeung, A., Streitberg, R., Francis, M.J. and Graham, M. (2016) Bacteroides pyogenes causing serious human wound infection from animal bites. Anaerobe, 42: 172-175.

20. Abba, Y., Ilyasu, Y.M. and Noordin, M.M. (2017) Isolation and identification of bacterial populations of zoonotic importance from captive non-venomous snakes in Malaysia. Microb. Pathog., 108: 49-54.

21. Bula-Rudas, F.J. and Olcott, J.L. (2018) Human and animal bites. Pediatr. Rev., 39(10): 490-500.

22. Goldstein, E.J.C, Citron, D.M., Tyrrell, K.L. and Leoncio, E.S. (2017) In vitro activity of pexiganan and 10 comparator antimicrobials against 234 isolates, including 93 Pasteurella species and 50 anaerobic bacterial isolates recovered from animal bite wounds. Antimicrob. Agents Chemother, 61(6): e00246-17.

23. Katica, M., Obradovic, Z., Ahmed, N.H. and Derviševic, E. 
(2019) Dog bites and their treatment in federation of Bosina and Herzegovina. Cyprus. J. Med. Sci., 4(2): 136-40.

24. Babalola, M.O. and Balogun, J.A. (2013) The ecology and potential health risk of the oral microflora of Python regius and Clelias cyntalina. Int. J. Microbiol. Res., 5(1): 349-356.

25. Drzewiecka, D. (2016) Significance and roles of Proteus spp. Bacteria in natural environments. Microb. Ecol., 72(4): 741-758.

26. Kaspar, U., von Lützau, A., Schlattmann, A., Roesler, U., Köck, R. and Becker, K. (2018) Zoonotic multidrug-resistant microorganisms among small companion animals in Germany. PloS One, 13(12): e0208364.

27. Hariharan, H., Matthew, V., Fountain, J., Snell, A., Doherty, D., King, B., Shemer, E., Oliveira, S. and Sharma, R.N. (2011) Aerobic Bacteria from mucous membranes, ear canals, and skin wounds of feral cats in Grenada, and the antimicrobial drug susceptibility of major isolates. Comp. Immunol. Microbiol. Infect. Dis., 34(2): 129-134.

28. Almansa Ruiz, J.C., Jonker, A., Bosman, A.M. and Steenkamp, G. (2018) Bacteria profile and antibiogram of the bacteria isolated from the exposed pulp of dog canine teeth. Vet. Rec., 183(3): 97.

29. Isaiah, A., Hoffmann, A.R., Kelley, R., Mundell, P., Steiner, J.M. and Suchodolski, J.S. (2017) Characterization of the nasal and oral microbiota of detection dogs. PloS One., 12(9): e0184899.

30. Hanif, Z., Taj, M.K., Rafiq, N., Taj, I., Tariq, N., Azam, S., Noor, S., Ali, S.A., Hussain, A. and Iqbal, K. (2019) Multidrug resistance of micro-organisms isolated from cat skin and saliva of Quetta city. Int. J. Entomol. Res., 4(6): 61-67.

31. Ujvári, B., Weiczner, R., Deim, Z., Terhes, G., Urbán, E., Tóth, A.R. and Magyar, T. (2019) Characterization of Pasteurella multocida strains isolated from human infections. Comp. Immunol. Microbiol. Infect. Dis., 63: 37-43.

32. Sager, M., Benten, W.P., Engelhardt, E., Gougoula, C. and Benga, L. (2015) Characterization of biofilm formation in Pasteurella pneumotropica and Actinobacillus muris isolates of mouse origin. PloS One, 10(10): e0138778.
33. Benga, L., Sager, M. and Christensen, H. (2018) From the Pasteurella pneumotropica complex to Rodentibacter spp.: An update on Pasteurella pneumotropica. Vet. Microbiol., 217: 121-134.

34. Vaneechoutte, M., Nemec, A., Kämpfer, P., Cools, P. and Wauters, G. (2015) Acinetobacter, Chryseobacterium, Moraxella, and other non-fermentative Gram-negative rods. In: Jorgensen, J.H. Pfaller, M.A., Carroll, K.C., Funke, G., Landry, M.L., Richter, S.S. and Warnock, D.W., editors. Manual of Clinical Microbiology. $11^{\text {th }}$ ed. ASM Press, Washington, DC, USA. p813-837.

35. Misic, A.M., Davis, M.F., Tyldsley, A.S., Hodkinson, B.P., Tolomeo, P., Hu, B., Nachamkin, I., Lautenbach, E., Morris, D.O. and Grice, E.A. (2015) The shared microbiota of humans and companion animals as evaluated from Staphylococcus carriage sites. Microbiome, 3: 2.

36. Abrahamian, F.M. and Goldstein, E.J.C. (2011) Microbiology of animal bite wound infections. Clin. Microbiol. Rev., 24(2): 231-246.

37. Ferreira, T.S., Moreno, L.Z., Felizardo, M.R., de Gobbi, D.D., Filsner, P.H., de Moura Gomes, V.T., Moreno, M. and Moreno, A.M. (2016) Pheno-and genotypic characterization of Pasteurella multocida isolated from cats, dogs and rabbits from Brazil. Comp. Immunol. Microbiol. Infect. Dis., 45: 48-52.

38. Awosile, B.B., McClure, J.T., Saab, M.E. and Heider, L.C. (2018) Antimicrobial resistance in Bacteria isolated from cats and dogs from the Atlantic Provinces, Canada from 1994-2013. Can. Vet. J., 59(8): 885-893.

39. Lappin, M.R., Blondeau, J., Boothe, D., Breitschwerdt, E.B., Guardabassi, L., Lloyd, D.H., Papich, M.G., Rankin, S.C., Sykes, J.E., Turnidge, J. and Weese, J.S. (2017) Antimicrobial use guidelines for treatment of respiratory tract disease in dogs and cats: Antimicrobial guidelines working group of the international society for companion animal infectious diseases. J. Vet. Intern. Med., 31(2): 279-294.

40. Michael, G.B., Bossé, J.T. and Schwarz, S. (2018) Antimicrobial resistance in Pasteurellaceae of veterinary origin. Microbiol. Spectr., 6(3): 0022.

$* * * * * * * *$ 